\title{
In-hospital Delay Increases the Risk of Perforation in Adults with Appendicitis
}

Busch, Mirjam ; Gutzwiller, Florian S ; Aellig, Sonja ; Kuettel, Rolf ; Metzger, Urs ; Zingg, Urs

\begin{abstract}
Background: The influence of in-hospital delay (time between admission and operation) on outcome after appendectomy is controversial. Methods: A total of 1,827 adult patients underwent open or laparoscopic appendectomy for suspected appendicitis in eleven Swiss hospitals between 2003 and 2006. Of these, 1,675 patients with confirmed appendicitis were included in the study. Groups were defined according in-hospital delay ( 12 vs. $>12 \mathrm{~h}$ ). Results: Delay $>12 \mathrm{~h}$ was associated with a significantly higher frequency of perforated appendicitis $(29.7$ vs. $22.7 \%$; $=0.010)$ whereas a delay of 6 or $9 \mathrm{~h}$ was not. Size of institution, time of admission, and surgical technique (laparoscopic vs. open) were independent factors influencing in-hospital delay. Admission during regular hours was associated with higher age, higher frequency of co-morbidity, and higher perforation rate compared to admission after hours. The logistic regression identified four independent factors associated with an increased perforation rate: age ( 65years vs. $>65$ years, odds ratio (OR) 4.5, $\mathrm{P}<0.001$ ); co-morbidity (Charlson index $>0$ vs. Charlson index $=0, \mathrm{OR}$ $2.3, \mathrm{P}<0.001$ ); time of admission (after hours vs. regular hours, OR 0.8, $\mathrm{P}=0.040$ ), in-hospital delay ( $>12$ vs. $12 \mathrm{~h}$, OR $1.5, \mathrm{P}=0.005)$. Perforation was associated with an increased reintervention rate (13.4 vs. $1.6 \% ; \mathrm{P}<0.001)$ and longer length of hospital stay (9.5 vs. 4.4days; $\mathrm{P}<0.001)$. Conclusions: In-hospital delay negatively influences outcome after appendectomy. In-hospital delay of more than $12 \mathrm{~h}$, age over 65 years, time of admission during regular hours, and the presence of co-morbidity are all independent risk factors for perforation. Perforation was associated with a higher reintervention rate and increased length of hospital stay
\end{abstract}

DOI: https://doi.org/10.1007/s00268-011-1101-z

Posted at the Zurich Open Repository and Archive, University of Zurich

ZORA URL: https://doi.org/10.5167/uzh-156736

Journal Article

Published Version

Originally published at:

Busch, Mirjam; Gutzwiller, Florian S; Aellig, Sonja; Kuettel, Rolf; Metzger, Urs; Zingg, Urs (2011). Inhospital Delay Increases the Risk of Perforation in Adults with Appendicitis. World Journal of Surgery, 35(7):1626-1633.

DOI: https://doi.org/10.1007/s00268-011-1101-z 


\title{
In-hospital Delay Increases the Risk of Perforation in Adults with Appendicitis
}

\author{
Mirjam Busch • Florian S. Gutzwiller • \\ Sonja Aellig • Rolf Kuettel • Urs Metzger • \\ Urs Zingg
}

Published online: 12 May 2011

(c) Société Internationale de Chirurgie 2011

\begin{abstract}
Background The influence of in-hospital delay (time between admission and operation) on outcome after appendectomy is controversial.

Methods A total of 1,827 adult patients underwent open or laparoscopic appendectomy for suspected appendicitis in eleven Swiss hospitals between 2003 and 2006. Of these, 1,675 patients with confirmed appendicitis were included in the study. Groups were defined according in-hospital delay ( $\leq 12$ vs. $>12 \mathrm{~h}$ ).

Results Delay $>12 \mathrm{~h}$ was associated with a significantly higher frequency of perforated appendicitis (29.7 vs. $22.7 \% ; P=0.010$ ) whereas a delay of 6 or $9 \mathrm{~h}$ was not. Size of institution, time of admission, and surgical technique (laparoscopic vs. open) were independent factors influencing in-hospital delay. Admission during regular hours was associated with higher age, higher frequency of co-morbidity, and higher perforation rate compared to admission after hours. The logistic regression identified four independent factors associated with an increased perforation rate: age ( $\leq 65$ years vs. $>65$ years, odds ratio (OR) 4.5, $P<0.001$ ); co-morbidity (Charlson index $>0$ vs. Charlson index $=0$, OR 2.3, $P<0.001$ ); time of admission (after hours vs. regular hours, OR 0.8 ,
\end{abstract}

M. Busch · U. Metzger · U. Zingg

Department of Surgery, Triemli Hospital Zurich,

Birmensdorferstrasse, 8063 Zurich, Switzerland

F. S. Gutzwiller · S. Aellig · R. Kuettel

"Outcome" Association Zurich,

Josefstrasse 92, 8005 Zurich, Switzerland

U. Zingg ( $\bowtie)$

University Hospital Basel, Spitalstrasse, 4031 Basel, Switzerland

e-mail: urs.zingg@spital-limmattal.ch
$P=0.040$ ), in-hospital delay ( $>12$ vs. $\leq 12 \mathrm{~h}$, OR 1.5, $P=0.005)$. Perforation was associated with an increased reintervention rate $(13.4$ vs. $1.6 \% ; P<0.001)$ and longer length of hospital stay (9.5 vs. 4.4 days; $P<0.001$ ).

Conclusions In-hospital delay negatively influences outcome after appendectomy. In-hospital delay of more than $12 \mathrm{~h}$, age over 65 years, time of admission during regular hours, and the presence of co-morbidity are all independent risk factors for perforation. Perforation was associated with a higher reintervention rate and increased length of hospital stay.

\section{Introduction}

Appendicitis is the most frequent surgical emergency. Open or laparoscopic resection of the inflamed appendix is the standard treatment. Perforation rates vary from 17 to $32 \%$ [1-6] and often mandate extended treatment with antibiotics, greater risk of complications, and longer hospital stays [4-12]. A number of risk factors for perforation have been described, such as age, co-morbidity, and gender [13-18].

Duration of inflammation of the appendix is related to the risk of perforation $[1,7,8,10,13,19-21]$. Time periods between onset of symptoms, medical assessment, diagnosis, and treatment are important. Delay to diagnosis is difficult to assess, especially in elderly patients who often have difficulties in reporting the onset of their symptoms. In-hospital delay is more easily quantified and has been analyzed in a number of articles, but with contradictory results $[1,7,8,10,11,19,22,23]$.

It is important to determine the effect of in-hospital delay on perforation rates to ascertain whether it is necessary to operate on patients with suspected appendicitis 
after hours. In many countries in central Europe, emergency appendectomies are still performed after hours, whereas in most English-speaking countries, off-hours surgery (especially nighttime surgery) is restricted to lifeor limb-threatening conditions. With increasing economic pressure on public health care, off-hour surgery might become less frequent. However, the costs incurred by the increased morbidity related to surgical delay may well exceed the savings gained by not operating after hours.

The aim of the present work, a prospective multicenter observational study, was to evaluate the influence of inhospital delay on perforation rates and clinical outcomes in adult patients with suspected appendicitis.

\section{Patients and methods}

Between January 2003 and January 2006, all adult patients treated with suspected appendicitis in eleven hospitals in Switzerland were included in a quality assessment project of the 'Outcome' Association. There were three tertiary referral centers (over 10,000 admissions per year) and seven regional hospitals (under 10,000 admissions per year). The 'Outcome' Association is a non-profit organization that was founded by the Health Authority of the State of Zurich to improve hospital care quality. The quality assessment project for patients undergoing treatment for appendicitis was approved by the State Health Authorities.

Inclusion criteria were adult patients with suspected appendicitis older than 16 years of age. Data on clinical condition, surgery, morbidity, and timing were collected by the treating medical staff. Questionnaires were controlled by the surgeon responsible for the collection of the 'Outcome' questionnaires in each department. A second control was performed by the data managers of the 'Outcome' association. Quality of life questionnaires were completed by the patients.

The diagnostic algorithm was based on personal history, clinical status, and laboratory findings. Routine radiological investigations are not part of the diagnostic process in any of the participating hospitals. The diagnostic algorithm was not standardized, and each surgical department of the participating hospitals was free to use additional investigations, such as ultrasound or computed tomography. No data were collected concerning the frequency of radiological investigations.

\section{Surgery}

Operations were performed either by standard open or laparoscopic techniques, according to departmental policies and surgeon preference. In all hospitals, a McBurney incision was the standard approach for open appendectomy. The study board did not impose any specific guidelines or prior training to surgeons. According to the intention to treat principle, conversions from the laparoscopic technique to the open technique were analyzed as "laparoscopic" operations.

Variables and outcome

The following variables were collected: age, gender, co-morbidities, size of the institution $(\leq 10,000$ admissions/ year, $>10,000$ admissions/year), type of appendicitis (acute, perforated), histological finding (appendicitis, tumor, normal), surgical technique, conversion rate, re-intervention rate, length of hospital stay (LOS), and in-hospital delay. In-hospital delay was defined as the time period between admittance to the hospital and operation.

Co-morbidities were classified according the method of Charlson et al. [24]. Histological assessment of all resected specimens was performed. Acute appendicitis was diagnosed by histopathological examination. Perforated appendicitis was diagnosed primarily intraoperatively and confirmed by histopathological examination. Intraoperative criteria were visible perforation or spilling of feces.

Concerning in-hospital delay, groups were defined as $\leq 12$ and $>12 \mathrm{~h}$. The $12 \mathrm{~h}$ cut-off was chosen because it allows a patient who is admitted in the evening to undergo surgical intervention the following morning, during regular working hours. Additionally this cut-off has been used in previous studies, thus allowing for direct comparisons [25]. The risk of perforation for cut-off values of $6,9,18$, and $24 \mathrm{~h}$ was also evaluated. Primary outcome was perforation rate. Secondary outcomes were reintervention rate and LOS. Additional analysis was performed to assess the influence of time of admission (regular hours vs. after hours) on outcomes. Regular hours were defined between 07:30 and 17:00, and after hours between 17:01 and 07:29. Public holidays and weekends were not differentiated from normal working days.

\section{Statistics}

All data was tested for Normal distribution with the Kolmogorov-Smirnov test. All data were parametric, and are presented as mean values with $95 \%$ Confidence Intervals (CIs). Comparison of data between the two patient groups was undertaken with chi-square tests for categorical data and Student's $t$-tests for continuous data. Univariate and multivariate logistic regression was performed to analyze influence of the following variables on the outcome perforation: Gender (male vs. female), size of institution ( $>10,000$ admissions vs. $\leq 10,000$ admissions), age ( $>65$ years vs. $\leq 65$ years), co-morbidity (Charlson 
index $>0$ vs. Charlson index $=0)$, in-hospital delay $(>12$ vs. $\leq 12 \mathrm{~h}$ ). Gender and institution were included a priori. Statistical significance was set at $P<0.05$. Statistical analyses were performed with MedCalc, version 9 for Windows.

\section{Results}

\section{Descriptives}

The overall collective consisted of 1,827 adult patients with suspected appendicitis. Mean age was 37.9 years (95\% CI 37.1-38.7 years). There were 984 (53.9\%) men and $843(46.1 \%)$ women in the cohort. Open and laparoscopic techniques were evenly distributed, with a conversion rate of $6.7 \%$ in the laparoscopic group. Descriptive details of the overall cohort are shown in Table 1. 1,675 (91.7\%) patients had confirmed appendicitis and were further evaluated. In 114 (6.2\%) patients with the clinical diagnosis of appendicitis a normal appendix was found at the time of histological assessment, and in $38(2.1 \%)$ patients histology revealed a tumor.

\section{Analysis of delay groups}

The analysis of all patients with confirmed appendicitis according to $12 \mathrm{~h}$ delay ( $\leq 12 \mathrm{vs}$. $>12 \mathrm{~h}$ ) between admission and surgery is shown in Table 2. Delay of more than $12 \mathrm{~h}$ was associated with a significantly higher number of patients with perforated appendicitis $(P=0.010)$. The

Table 1 Descriptive data of overall collective of patients with appendectomy for clinical diagnosis of appendicitis $(n=1,827)$

\begin{tabular}{ll}
\hline Histological finding & \\
Acute appendicitis, \% & $1,273(69.7)$ \\
Perforated appendicitis, \% & $402(22.0)$ \\
Tumor, \% & $38(2.1)$ \\
Normal appendix, \% & $114(6.2)$ \\
Surgical technique & \\
Open appendectomy, \% & $898(49.2)$ \\
Laparoscopic appendectomy, \% & $929(50.8)$ \\
Conversion, \% & $62(6.7)$ \\
Co-morbidity & \\
Charlson index $=0, \%$ & $1705(93.3)$ \\
Charlson index $>0, \%$ & $122(6.7)$ \\
Size of institutions & \\
$\leq 10,000$ admissions/year, \% & $500(27.4)$ \\
$>10,000$ admissions/year, \% & $1327(72.6)$ \\
Mean in-hospital delay, hours (95\% CI) & $9.4(8.8-10.0)$ \\
Mean length of hospitalization, days (95\% CI) & $5.6(5.4-5.8)$ \\
\hline
\end{tabular}

95\% CI 95\% confidence interval
$12 \mathrm{~h}$ delay was also significantly associated with size of institution, time of admission, type of surgery, conversion rate, and LOS. The analysis of risk of perforation with additional delay strata showed no association of perforation with the 6 or the $9 \mathrm{~h}$ delay. However, the risk of perforation increased with increase of delay (Table 3 ).

Patients with a delay $>12 \mathrm{~h}$ were more often admitted to the hospital after hours. Analysis of the influence of time of admission on surgical delay showed that patients who were admitted during regular hours were older (regular hours age $>65$ years $10.9 \%$ vs. after hours age $>65$ years $6.4 \% ; P=0.002$ ), and had more co-morbidities (regular hours Charlson index $>18.0 \%$ vs. after hours Charlson index $>15.3 \% ; P=0.040)$ and also a higher perforation rate (regular hours 248 patients (26.4\%) vs. after hours 154 patients (20.9\%); $P=0.012$ ).

Logistic regression analysis of factors influencing in-hospital delay is shown in Table 4. Size of institution, time of admission, and type of surgical technique were all independent predictors of an in-hospital delay of more than $12 \mathrm{~h}$.

Acute versus perforated appendicitis and logistic regression

The groups according to presence or absence of perforation showed distinct differences in a number of variables and outcomes (Table 5). Reintervention rates and LOS were significantly higher in the perforation group. Patients with perforated appendicitis were older, had more co-morbidities, and experienced a longer delay prior to surgical intervention. However, patients admitted after hours were less likely to have perforated appendicitis. Logistic regression analysis identified age, co-morbidity, time of admission, and in-hospital delay to be independent factors influencing perforation rate (Table 6).

\section{Discussion}

This study of 1,675 adult patients undergoing appendectomy for appendicitis shows that an in-hospital delay of $12 \mathrm{~h}$ or more was associated with a significantly higher perforation rate and longer LOS. The 6 and $9 \mathrm{~h}$ delay was not associated with an increased risk of perforation, whereas the percentage of patients with perforation increased with in-hospital delays of more than $12 \mathrm{~h}$ (18 and $24 \mathrm{~h})$. Older age, existing co-morbidity, and-to a lesser extent-time of admission are also independent factors associated with a higher perforation rate of the appendix and thus also influence the clinical outcome. Perforation itself was associated with significantly higher re-intervention rate, conversion rates, and longer LOS. 
Table 2 Analysis of all patients with appendicitis $(n=1,675)$ stratified according in-hospital delay

A cutoff of $12 \mathrm{~h}$ was selected as it would allow delaying surgery until normal working hours if a patient was admitted during off hours

\begin{tabular}{|c|c|c|c|}
\hline & $\begin{array}{l}\text { Delay } \leq 12 \mathrm{~h} \\
(n=1,355)\end{array}$ & $\begin{array}{l}\text { Delay }>12 \mathrm{~h} \\
(n=320)\end{array}$ & $P$ Value \\
\hline Age & & & 0.833 \\
\hline$\leq 65$ years, $\%$ & $1,233(91.0)$ & $293(91.6)$ & \\
\hline$>65$ years, $\%$ & $122(9.0)$ & $27(8.4)$ & \\
\hline Gender & & & 0.678 \\
\hline Male, \% & $761(56.2)$ & $175(54.7)$ & \\
\hline Female, $\%$ & $594(43.8)$ & $145(45.3)$ & \\
\hline Co-morbidity & & & 0.671 \\
\hline Charlson index $=0, \%$ & $1,265(93.4)$ & $296(92.5)$ & \\
\hline Charlson index $>0, \%$ & $90(6.6)$ & $24(7.5)$ & \\
\hline Size of institutions & & & 0.009 \\
\hline$\leq 10,000$ admissions/year $(\%)$ & $380(28.0)$ & $66(20.6)$ & \\
\hline$>10,000$ admissions/year $(\%)$ & $975(72.0)$ & $254(79.4)$ & \\
\hline Time of admission & & & $<0.001$ \\
\hline Regular hours (07:30-17:00) & $791(58.4)$ & $149(46.6)$ & \\
\hline After hours (17:01-07:29) & $564(41.6)$ & $171(53.4)$ & \\
\hline Type of appendicitis & & & 0.010 \\
\hline Acute appendicitis, $\%$ & $1,048(77.3)$ & $225(70.3)$ & \\
\hline Perforated appendicitis, $\%$ & $307(22.7)$ & $95(29.7)$ & \\
\hline Surgical technique & & & 0.012 \\
\hline Open appendectomy, $\%$ & $714(52.7)$ & $143(44.7)$ & \\
\hline Laparoscopic appendectomy, $\%$ & $641(47.3)$ & $177(55.3)$ & \\
\hline Conversion & & & 0.015 \\
\hline No, $\%$ & $1,315(97.1)$ & $301(94.1)$ & \\
\hline Yes, \% & $40(2.9)$ & $19(5.9)$ & \\
\hline Reintervention overall & & & 0.120 \\
\hline No, $\%$ & $1,300(95.9)$ & $300(93.8)$ & \\
\hline Yes, \% & $55(4.1)$ & $20(6.2)$ & \\
\hline Reintervention for wound infection & & & 0.140 \\
\hline No, $\%$ & $1,326(97.9)$ & $308(96.3)$ & \\
\hline Yes, \% & $29(2.1)$ & $12(3.7)$ & \\
\hline Reintervention for hematoma & & & 0.852 \\
\hline No, $\%$ & $1,347(99.4)$ & $319(99.7)$ & \\
\hline Yes, \% & $8(0.6)$ & $1(0.3)$ & \\
\hline Reintervention for abscess & & & 0.032 \\
\hline No, $\%$ & $1,338(98.8)$ & $310(96.9)$ & \\
\hline Yes, \% & $17(1.2)$ & $10(3.1)$ & \\
\hline Reintervention for ileus & & & 0.852 \\
\hline No, $\%$ & $1,347(99.4)$ & $319(99.7)$ & \\
\hline Yes, \% & $8(0.6)$ & $1(0.3)$ & \\
\hline Mean length of hospitalization, days $(95 \% \mathrm{CI})$ & $5.3(5.1-5.5)$ & $6.8(6.3-7.3)$ & $<0.001$ \\
\hline
\end{tabular}

Delay to surgery was associated with a number of other variables, including size of institution, type of surgical technique, time of admission, and conversion rate. Delay $>12 \mathrm{~h}$ between admission and operation occurred significantly more often in large institutions. This is likely due to a larger number of emergency cases, many of which are complex and lengthy procedures. Appendicitis patients will often have a lower priority compared to neurosurgical, trauma, and vascular emergencies. Smaller hospitals do not have to deal with these more urgent and complex cases, and will have a greater capacity to perform these smaller procedures in a timely manner. The logistic regression showed that laparoscopic appendectomy was an independent predictor for in-hospital delay. Patients in the $>12 \mathrm{~h}$ 
Table 3 The analysis of risk of perforation with all delay strata $(6,9,12,18$, and $24 \mathrm{~h})$

\begin{tabular}{|c|c|c|c|}
\hline & Delay $\leq 6 \mathrm{~h}(n=801)$ & Delay $>6$ h $(n=874)$ & $P$ value \\
\hline Acute appendicitis, \% & $622(77.7)$ & $651(74.5)$ & 0.145 \\
\hline \multirow[t]{2}{*}{ Perforated appendicitis, \% } & $179(22.3)$ & $223(25.5)$ & \\
\hline & Delay $\leq 9 \mathrm{~h}(n=1,159)$ & Delay $>9$ h $(n=516)$ & $P$ value \\
\hline Acute appendicitis, \% & 888 (76.6) & $385(74.6)$ & 0.409 \\
\hline \multirow[t]{2}{*}{ Perforated appendicitis, $\%$} & $271(23.4)$ & $131(25.4)$ & \\
\hline & Delay $\leq 12 \mathrm{~h}(n=1,355)$ & Delay $>12$ h $(n=320)$ & $P$ value \\
\hline Type of appendicitis & & & 0.010 \\
\hline Acute appendicitis, $\%$ & $1,048(77.3)$ & $225(70.3)$ & \\
\hline \multirow[t]{2}{*}{ Perforated appendicitis, \% } & $307(22.7)$ & $95(29.7)$ & \\
\hline & Delay $\leq 18$ h $(n=1,497)$ & Delay > 18 h $(n=178)$ & $P$ value \\
\hline Acute appendicitis, $\%$ & $1,153(77.0)$ & $120(67.4)$ & 0.006 \\
\hline \multirow[t]{2}{*}{ Perforated appendicitis, $\%$} & $344(23.0)$ & $58(32.6)$ & \\
\hline & Delay $\leq 24 \mathrm{~h}(n=1,564)$ & Delay $>24$ h $(n=111)$ & $P$ value \\
\hline Acute appendicitis, \% & $1,200(76.7)$ & $73(65.8)$ & 0.013 \\
\hline Perforated appendicitis, $\%$ & $364(23.3)$ & $38(34.2)$ & \\
\hline
\end{tabular}

Table 4 Logistic regression analysis (univariate and multivariate) of factors influencing the in-hospital delay

\begin{tabular}{|c|c|c|c|c|}
\hline & \multicolumn{2}{|l|}{ Univariate } & \multicolumn{2}{|l|}{ Multivariate } \\
\hline & Odds ratio $(95 \% \mathrm{CI})$ & $P$ value & Odds ratio $(95 \% \mathrm{CI})$ & $P$ value \\
\hline Size of institution ( $>10,000$ admissions vs. $<10,000$ admissions) & $1.50(1.12-2.02)$ & 0.006 & $1.54(1.14-2.08)$ & 0.005 \\
\hline Time of admission (after hours [17:01-07:29] vs. regular hours [07:30-17:00]) & $1.61(1.26-2.06)$ & $<0.001$ & $1.56(1.22-2.00)$ & $<0.001$ \\
\hline Surgical technique (laparoscopic vs. open appendectomy) & $1.38(1.08-1.76)$ & 0.010 & $1.41(1.10-1.81)$ & 0.006 \\
\hline
\end{tabular}

delay group underwent laparoscopic surgery more often than open surgery, which may represent the fact that laparoscopy was used preferentially as a diagnostic tool in patients who were initially observed. The conversion rate was higher in the delayed group, most likely secondary to the higher perforation rate. No data on reasons for conversion were collected. Also, it was not possible to retrospectively access the case notes recorded for the patients who underwent a conversion.

Next to the delay between admission and surgery, the timing of admission played an additional role. Patients admitted during regular hours were older and had more co-morbidities. The perforation rate was significantly higher during regular hours. Time of admission was an independent predictor of in-hospital delay as well as perforation; however, only with borderline significance. The three other independent factors - age, co-morbidity and in-hospital delay-showed higher odds ratios and seem to have had more influence on the perforation rate than time of admission. Still, patients admitted during regular hours seem to have waited longer, which may be explained by the fact that regular operation lists are running and moderately urgent procedures such as appendectomy have to wait.

Perforation significantly influenced not only surgical technique and conversion rate but, more importantly, clinical outcome. Patients with perforation were more likely to undergo open appendectomy. This may have been due to higher rates of peritonitis in patients with perforation. However, this interpretation is speculative, as this study did not assess the findings of the clinical examination. In patients with perforation who underwent laparoscopic appendectomy, conversion rates were also significantly higher.

The reintervention rate was higher in patients with perforation. Length of hospital stay was more than double in perforated appendicitis. Next to the obvious impact on a patient's health and overall cosmesis of the operation, a perforation was certainly also associated with higher health 
Table 5 Analysis of all patients with appendicitis $(n=1,675)$ stratified according presence of perforation

\begin{tabular}{|c|c|c|c|}
\hline & $\begin{array}{l}\text { No perforation } \\
(n=1,273)\end{array}$ & $\begin{array}{l}\text { Perforation } \\
(n=402)\end{array}$ & $P$ value \\
\hline Age & & & $<0.001$ \\
\hline$\leq 65$ years, $\%$ & $1,212(95.2)$ & $314(78.1)$ & \\
\hline$>65$ years, $\%$ & $61(4.8)$ & $88(21.9)$ & \\
\hline Gender & & & 0.365 \\
\hline Male, \% & $703(55.2)$ & $233(58.0)$ & \\
\hline Female, $\%$ & $570(44.8)$ & $169(42.0)$ & \\
\hline Co-morbidity & & & $<0.001$ \\
\hline Charlson index $=0, \%$ & $1,218(95.7)$ & $343(85.3)$ & \\
\hline Charlson index $>0, \%$ & $55(4.3)$ & $59(14.7)$ & \\
\hline Size of institutions & & & 0.850 \\
\hline$\leq 10,000$ admissions/year, $\%$ & $337(26.5)$ & $109(27.1)$ & \\
\hline$>10,000$ admissions/year, $\%$ & $936(73.5)$ & $293(72.9)$ & \\
\hline Time of admission & & & 0.012 \\
\hline Regular hours (07:30-17:00), \% & $692(54.4)$ & $248(61.7)$ & \\
\hline After hours (17:01-07:29), \% & $581(45.6)$ & $154(38.3)$ & \\
\hline Delay & & & 0.010 \\
\hline$\leq 12 \mathrm{~h}, \%$ & $1,048(82.3)$ & $307(76.4)$ & \\
\hline$>12 \mathrm{~h}, \%$ & $225(17.7)$ & $95(23.6)$ & \\
\hline Surgical technique & & & $<0.001$ \\
\hline Open appendectomy, \% & $614(48.2)$ & $243(60.5)$ & \\
\hline Laparoscopic appendectomy, \% & $659(51.8)$ & $159(39.5)$ & \\
\hline Conversion & & & $<0.001$ \\
\hline No, $\%$ & $1,253(98.4)$ & $363(90.3)$ & \\
\hline Yes, \% & $20(1.6)$ & $39(9.7)$ & \\
\hline Reintervention overall & & & $<0.001$ \\
\hline No, $\%$ & $1,252(98.4)$ & $348(86.6)$ & \\
\hline Yes, \% & $21(1.6)$ & $54(13.4)$ & \\
\hline Reintervention for wound infection & & & $<0.001$ \\
\hline No, $\%$ & $1,262(99.1$ & $372(92.5)$ & \\
\hline Yes, \% & $11(0.9)$ & $30(7.5)$ & \\
\hline Reintervention for hematoma & & & 0.067 \\
\hline No, $\%$ & $1,269(99.7)$ & $397(98.8)$ & \\
\hline Yes, \% & $4(0.3)$ & $5(1.2)$ & \\
\hline Reintervention for abscess & & & $<0.001$ \\
\hline No, $\%$ & 1,268 (99.6) & $380(94.5)$ & \\
\hline Yes, \% & $5(0.4)$ & $22(5.5)$ & \\
\hline Reintervention for ileus & & & 0.009 \\
\hline No, $\%$ & $1,271(99.8)$ & $396(98.5)$ & \\
\hline Yes, \% & $2(0.2)$ & $6(1.5)$ & \\
\hline Mean length of hospitalization, days $(95 \% \mathrm{CI})$ & $4.4(4.2-4.5)$ & $9.5(9.0-10.1)$ & $<0.001$ \\
\hline
\end{tabular}

care costs, from the additional reinterventions, the increased LOS, and the additional use of antibiotics.

Patients who suffered from perforation were significantly older, more frequently had co-morbidities, and were more likely to have delayed surgery. These findings are consistent with observations of other studies showing that older patients present with more advanced forms of appendicitis [7, 9, 13-18, 22]. The logistic regression showed that age was the most important factor influencing the perforation rate, followed by co-morbidity and delay. Patients over the age of 65 had a 4.5 times higher risk of perforation compared to those under 65 . Patients with one or more co-morbidity had more than a twofold risk for perforation, whereas delay of $12 \mathrm{~h}$ or more increased the risk for perforation by a factor of 1.5 . The influence of age on perforation rate has been addressed in a number of 
Table 6 Logistic regression analysis (univariate and multivariate) of factors influencing the perforation rate

\begin{tabular}{|c|c|c|c|c|}
\hline & \multicolumn{2}{|l|}{ Univariate } & \multicolumn{2}{|l|}{ Multivariate } \\
\hline & $\begin{array}{l}\text { Odds ratio } \\
(95 \% \mathrm{CI})\end{array}$ & $P$ value & $\begin{array}{l}\text { Odds ratio } \\
(95 \% \mathrm{CI})\end{array}$ & $P$ value \\
\hline Gender (male vs. female) & $1.12(0.9-1.4)$ & 0.336 & & \\
\hline $\begin{array}{l}\text { Size of institution }(>1,000 \text { admissions } \\
\text { vs. }<10,000 \text { admissions })\end{array}$ & $0.97(0.75-1.25)$ & 0.800 & & \\
\hline Age (>65 vs. $\leq 65)$ & $5.57(3.93-7.90)$ & $<0.001$ & $4.48(3.10-6.47)$ & $<0.001$ \\
\hline $\begin{array}{l}\text { Co-morbidity }(\text { Charlson index }>0 \\
\text { vs. Charlson index }=0)\end{array}$ & $3.81(2.59-5.61)$ & $<0.001$ & $2.34(1.53-3.56)$ & $<0.001$ \\
\hline $\begin{array}{l}\text { Time of admission (after hours 17:01-07:29 } \\
\text { vs. regular hours 07:30-17:00) }\end{array}$ & $0.74(0.59-0.93)$ & 0.010 & $0.78(0.61-0.99)$ & 0.044 \\
\hline Delay (>12 vs. $\leq 12$ h) & $1.44(1.10-1.89)$ & 0.008 & $1.54(1.16-2.04)$ & 0.003 \\
\hline
\end{tabular}

studies. One of the major reasons might be delay to diagnosis, as elderly patients wait longer to seek medical care [7, 17, 22, 26]. Another possible reason might be emergency department wait times. The number of possible differential diagnoses in an elderly patient is greater than that for younger patients, and additional preoperative management issues such as correction of renal impairment, reversal of anticoagulation, or correction of electrolyte imbalances might have further delayed the operation. Also, the use of additional imaging, such as computed tomography, may be more frequent in elderly and co-morbid patients, causing further delays.

It is important to acknowledge that there might also be a selection of patients with perforation present, because some patients with non-perforated appendicitis had a spontaneous resolution. There is circumstantial evidence suggesting that not every appendicitis progresses towards perforation and that resolution of nonperforated appendicitis may be more common than previously expected [27].

The influence of in-hospital delay has been analyzed in a number of studies [7, 8, 10, 11, 19, 22, 23, 25]. In contrast to delay to diagnosis, which has been accepted as an important factor associated with more severe appendicitis, analyses of in-hospital delay are contradictory [7, 10, 11, 19, 22]. Indeed, some studies report shorter in-hospital delays in patients with perforated appendicitis, most likely because the more severe clinical findings expedited patient treatment [8, 23]. A recent retrospective analysis of over 1,000 cases showed that severity of pathology and morbidity in adult patients was time dependent [25]. The authors concluded that appendectomy should be performed as expeditiously as possible. Our findings underline these results, but show that age and co-morbidity are also important factors. Especially in elderly patients and those with co-morbidities, any delay of surgery should be avoided. However, performing appendectomy without delay will result in more frequent off-hour surgery, and this may result in more unsupervised operating by surgical trainees. The 2003 report from the United Kingdom of the National Confidential Inquiry into Perioperative Deaths
(NCEPOD) showed that there was substantially less supervision by consultants in the evenings and after hours compared to daytime surgery [28]. This must be considered when a more timely surgery protocol for suspected appendicitis is implemented.

Some limitations merit mention. In the present study public holidays and weekends were not differentiated from normal working days. The study only addressed in-hospital delay, and not patient delay (time between onset of symptoms and diagnosis). Patient delay is difficult to determine, especially in elderly patients who might not be able to give an appropriate history of symptoms. The collective in the present study consisted of over 1,800 adult patients, and patient delay is likely to be evenly distributed between the groups and might therefore not have influenced the results. Another limitation is the lack of some preoperative and perioperative information, such as the frequency of preoperative antibiotic therapy, extent of peritonitis, and the number of patients who underwent open appendectomy via midline laparotomy. Antibiotic therapy has been shown to be a feasible alternative for the treatment of acute appendicitis [29]. In Switzerland, antibiotic therapy is generally started perioperatively and is only continued postoperatively if abscess, phlegmon, or perforation is present. However, no standardized protocol was used in the present study, and this might have influenced the results.

\section{Conclusions}

In-hospital delay negatively influences outcome after appendectomy in adults. The findings of the present study indicate that in-hospital delay of more than $12 \mathrm{~h}$, age over 65 years, and the presence of co-morbidity are independent risk factors for perforation. A 6 or 9 h delay was not associated with an increased perforation rate. With increasing delay, the percentage of patients with perforation increased as well. Perforation is associated with a higher re-intervention rate and increased LOS. In elderly patients with 
co-morbidity and suspected appendicitis, a delay of surgery of more than $12 \mathrm{~h}$ should be avoided.

Acknowledgments The authors are grateful to David I. Watson, M.D., and Sarah Thompson, M.D., for critical review of the manuscript. The authors are also grateful to the surgeons who contributed patient records for this study. The study was funded by the 'Outcome' Association Zurich, Switzerland.

Conflict of interest None.

\section{Appendix}

List of hospitals (surgeons-in-chief) that participated in the study: Cantonal Hospital of Winterthur (Prof. M. Decurtins), Triemli Hospital Zürich (Prof. U. Metzger), University Hospital Zürich (Prof. P.-A. Clavien), Hospital Affoltern (Dr. M. Wiens), Waid Hospital Zürich (Dr. S. Wildi), Hospital Männedorf (Dr. J. Wydler), Hospital Solothurn (Dr J.-P. Barras), Hospital Olten (Prof. M. Zuber), Hospital Wetzikon (Dr. R. Stieger), Hospital Zollikerberg (Dr. S. Müller), Hospital Zimmerberg (Dr. P. Guyer). All surgeons-in-chief read and approved the manuscript.

\section{References}

1. Kearney D, Cahill RA, O'Brien E et al (2008) Influence of delays on perforation risk in adults with acute appendicitis. Dis Colon Rectum 51:1823-1827

2. SCOAP Collaborative, Cuschieri J, Florence M, Flum DR et al (2008) Negative appendectomy and imaging accuracy in the Washington State Surgical Care and Outcomes Assessment Program. Ann Surg 248:557-563

3. Hale DA, Jaques DP, Molloy M et al (1997) Appendectomy. Improving care through quality improvement. Arch Surg 132: 153-157

4. Sleem R, Fisher S, Gestring M et al (2009) Perforated appendicitis: is early laparoscopic appendectomy appropriate? Surgery 146:731-737

5. Pittman-Waller VA, Myers JG, Stewart RM et al (2000) Appendicitis: why so complicated? Analysis of 5755 consecutive appendectomies. Am Surg 66:548-554

6. Colson M, Skinner KA, Dunnington G (1997) High negative appendectomy rates are no longer acceptable. Am J Surg 174: 723-726

7. Eldar S, Nash E, Sabo E et al (1997) Delay of surgery in acute appendicitis. Am J Surg 173:194-198

8. Temple CL, Huchcroft SA, Temple WJ (1995) The natural history of appendicitis in adults. A prospective study. Ann Surg 221: 278-281
9. Fahim F, Shirjeel S (2005) A comparison between presentation time and delay in surgery in simple and advanced appendicitis. J Ayub Med Coll Abbottabad 17:37-39

10. Maroju NK, Robinson Smile S, Sistla SC et al (2004) Delay in surgery for acute appendicitis. ANZ J Surg 74:773-776

11. Von Titte SN, McCabe CJ, Ottinger LW (1996) Delayed appendectomy for appendicitis: causes and consequences. Am J Emerg Med 14:620-622

12. Omundsen M, Dennett E (2006) Delay to appendicectomy and associated morbidity: a retrospective review. ANZ J Surg 76: $153-155$

13. Hardin DM Jr (1999) Acute appendicitis: review and update. Am Fam Physician 60:2027-2034

14. Preston CA, Karch SB (1989) The influence of gender and use of barium enema on morbidity in acute appendicitis. Am J Emerg Med 7:253-255

15. Antevil J, Rivera L, Langenberg B et al (2004) The influence of age and gender on the utility of computed tomography to diagnose acute appendicitis. Am Surg 70:850-853

16. Agafonoff S, Hawke I, Khadra M et al (1987) The influence of age and gender on normal appendicectomy rates. ANZ J Surg 57:843-846

17. Franz MG, Norman J, Fabri PJ (1995) Increased morbidity of appendicitis with advancing age. Am Surg 61:40-44

18. Lunca S, Bouras G, Romedea NS (2004) Acute appendicitis in the elderly patient: diagnostic problems, prognostic factors and outcomes. Rom J Gastroenterol 13:299-303

19. Hansson LE, Laurell H, Gunnarson U (2008) Impact of time in the development of acute appendicitis. Dig Surg 25:394-399

20. Abou-Nukta F, Bakhos C, Arroyo K et al (2006) Effects of delaying appendicectomy for acute appendicitis for 12 to 24 hours. Arch Surg 141:504-507

21. Bickell N, Aufses AH, Rojas M et al (2006) How time affects the risk of rupture in acute appendicitis. J Am Coll Surg 202:401-406

22. Chung CH, Ng CP, Lai KK (2000) Delays by patients, emergency physicians, and surgeons in the management of acute appendicitis: retrospective study. Hong Kong Med J 6:254-259

23. Papaziogas B, Tsiaousis P, Koutelidakis I et al (2009) Effect of time on risk of perforation in acute appendicitis. Acta Chir Belg 109:75-80

24. Charlson ME, Pompei P, Ales KL et al (1987) A new method of classifying prognostic co-morbidity in longitudinal studies: development and validation. J Chronic Dis 40:373-383

25. Ditillo MF, Dziura JD, Rabinovici R (2006) Is it safe to delay appendectomy in adults with acute appendicitis? Ann Surg 244: 656-660

26. Burns RP, Cochran JL, Russell WL et al (1985) Appendicitis in mature patients. Ann Surg 201:695-704

27. Andersson RE (2007) The natural history and traditional management of appendicitis revisited: spontaneous resolution and predominance of prehospital perforations imply that a correct diagnosis is more important than early diagnosis. World J Surg 31:86-92. doi:10.1007/s00268-006-0056-y

28. Cullinane M, Gray AJG, Hargraves CMK et al (2003) The 2003 report of the national confidential inquiry into perioperative deaths, pp 1-128. www.ncepod.org.uk. Accessed April 2011

29. Simillis C, Symeonides P, Shorthouse AJ et al (2010) A metaanalysis comparing conservative treatment versus acute appendectomy for complicated appendicitis (abscess or phlegmon). Surgery 147:818-829 